\title{
PREPARATION AND ANALYSIS OF QUASICRYSTALLINE PHASES BY HIGH ENERGY BALL MILLING AND X-RAY DIFFRACTION
}

\author{
Salimon A.I. ${ }^{\dagger}$, Korsunsky A.M. ${ }^{\dagger}$, Shelekhov E.V. ${ }^{*}$, Sviridova T.A. ${ }^{\ddagger}$ \\ ${ }^{\dagger}$ Department of Mechanical, Materials and Manufacturing Engineering, \\ University of Newcastle, Newcastle upon Tyne NE1 7RU, United Kingdom \\ $\ddagger$ Department of X-ray and Metal Physics, Moscow Institute for Steel and Alloys, \\ Moscow, Lenin av. 4, Russia
}

Keywords: quasicrystals, X-ray diffraction, mechanical alloying.

\begin{abstract}
The consequences of solid-state reactions in mechanically alloyed $\mathrm{Al}-\mathrm{Cu}-\mathrm{Fe}$ powders were studied using advanced techniques of X-ray diffraction pattern interpretation. A set of intermetallic phases was identified which appeared as a result of mechanical alloying and subsequent annealing. These intermetallics were the intermediate products formed during to gradual mechanical and thermal homogenisation and excitation.

The quantitative phase composition of mechanically alloyed powders was determined using interactively controlled database phase analysis, fitting procedures and modelling of X-ray patterns for different structures. The analysis allowed us to optimise the processing route, and identify the conditions promoting the formation of single phase quasicrystalline powder. Single phase powders of the quasicrystalline $\mathrm{Al}_{6} \mathrm{Cu}_{2} \mathrm{Fe}$ intermetallic ( $\psi$-phase) were obtained from the mixture of elemental powders $\mathrm{Al}_{70} \mathrm{Cu}_{20.3} \mathrm{Fe}_{9.7}$ after a short time milling and annealing at $800{ }^{\circ} \mathrm{C}$ under argon.
\end{abstract}

\section{INTRODUCTION}

Due to their unusual structure and properties, quasicrystalline (QC) alloys present an attractive material choice in a wide field of applications, such as hydrogen storage, solar power, thermal insulation, surface engineering, etc. [1,2]. Serious obstacles must be overcome in developing applications for these materials, which are associated with metastability of the most quasicrystalline phases, and extremely narrow homogeneity ranges of the stable quasicrystals. The brittleness of QC materials implies that successful uses may be sought in combination with other materials, for example, in the form of thin surface coatings.

Up to date, relatively few research papers have appeared $[3,4]$ aimed at identifying the principles and practical methods which could become suitable to the manufacture of commercially viable products.

QC materials can be prepared using sophisticated crystal growth techniques, which are highly sensitive to the precise composition, and expensive. Alternatively, rapid cooling from molten state can be used. Mechanical alloying (MA) is a versatile technique capable of producing metastable and non-equilibrium phases, and may offer a cheap viable method of preparing QC alloy powders suitable for subsequent manipulation. The quasicrystalline phase in the recently well-studied $\mathrm{Al}-\mathrm{Cu}-\mathrm{Fe}$ system $[5,6]$ is stable up to the melting temperature. This important property is the cause of interest in this material, in combination with the fact that the alloying elements are easily available and cheap.

In the present study we aimed to investigate the details of the solid-state transformations taking place during mechanical alloying and subsequent annealing of the powders, within the 
composition region close to the $\psi$-phase $\left(\mathrm{Al}_{6} \mathrm{Cu}_{2} \mathrm{Fe}\right.$ intermetallic) phase domain. The analysis of these transformations, and optimisation of precursor composition and processing conditions, allowed us to obtain effectively single phase ( $99 \%$ volume fraction) quasicrystalline powders.

Powder samples are naturally well-suited for structural and phase characterisation using laboratory X-ray diffraction techniques. In this paper, we use the patterns analysis by curve fitting and decomposition, and modelling of powder diffraction patterns for structural interpretation.

\section{EXPERIMENTAL}

Elemental powders of pure (99.9\%, nominal particle sizes smaller than $150 \mu \mathrm{m}) \mathrm{Al}, \mathrm{Cu}$ and $\mathrm{Fe}$ were prepared by mixing in different compositions for subsequent mechanical alloying. Mechanical alloying was performed using a vertical vibrational mill. A cylindrical vial (working volume: diameter $\varnothing 26 \mathrm{~mm}$, height $40 \mathrm{~mm}$ ) of heat treated tool steel was driven in oscillatory motion at the frequency of $50 \mathrm{~Hz}$, and amplitudes of 6 or $9 \mathrm{~mm}$ (settings 1 and 2 respectively). A powder charge $(2.5 \mathrm{~g})$ was sealed in the vial together with the grinding media ( 60 bearing balls of $\varnothing 4.9 \mathrm{~mm}$, of total weight $30 \mathrm{~g}$ ). In order to reduce the sticking of ductile Al powder to the vial walls, the vial was sealed under normal atmosphere. If the vial were to be opened and sealed several time during milling, accumulation of oxygen would have taken place. Therefore, when the influence of milling time was investigated, excessive oxygen contamination was avoided by loading a fresh charge and processing it for the full duration of the experiment. A straightforward calculation shows that in this case no more than 0.5 at $\%$ of $\mathrm{Al}$ may be lost from the milled alloy by binding with oxygen.

Phase composition of the powders was characterised in the as-milled condition, as well as after annealing at different temperatures, using laboratory X-ray diffractometer DRON-4 with monochromatic $\mathrm{Co}-\mathrm{K} \alpha$ or $\mathrm{Ni}-\mathrm{K} \alpha$ radiation in step-counting mode. In order to carry out phase analysis, a specially written computer software package was used, which included programs for peak profile fitting, multiple and overlapping peak fitting, and X-ray pattern simulation for phases with known structure [7].

Solid-state transformations taking place in the as-milled powder during heating were investigated using METTLER FP90 differential scanning calorimetry (DSC) and the Stanton Redcroft differential thermal analysis (DTA) machines. The heating rate of $10 \mathrm{~K} / \mathrm{min}$ in argon atmosphere was applied in both cases. A set of samples was prepared by heating the powders above observed exothermic peaks, maintaining for different times at a certain temperature, followed by cooling at the same rate $(10 \mathrm{~K} / \mathrm{min})$.

The powder microstructure was studied using a JEOL JSM-35 scanning electron microscope operated at $15 \mathrm{kV}$. The samples' chemical homogeneity, i.e. the spatial distribution of elements, was monitored using an EDX attachment.

\section{RESULTS AND DISCUSSION}

Eckert et al in [8] demonstrated that obtaining the quasicrystalline icosahedral phase in the Al$\mathrm{Cu}-\mathrm{Fe}$ system is possible by means of a combination of mechanical alloying and heat treatment. From the X-ray patterns presented in [9] one may conclude that, in the $\mathrm{Al}-\mathrm{Cu}-\mathrm{Fe}$ system, the formation of the QC phase perhaps takes place immediately during MA. Subsequent heating appeared to transform the as-milled material into a mixture of the F-type quasicrystalline phase with an unidentified phase. A number of other crystalline phases (mainly unidentified) were also reported in both papers. However, it appears that neither in [8], nor in [9] the quasicrystalline material had been obtained for the $\mathrm{Al}_{65} \mathrm{Cu}_{20} \mathrm{Fe}_{15}$ composition in single phase form. It is important to note that, according to [2], the presence of a second phase leads to significant processing difficulties for the quasicrystalline material.

The existence domain of the $\psi$-phase is quite narrow, and borders on the domains $[5,6]$ of several other crystalline phases (a monoclinic $\lambda$-phase $\mathrm{Al}_{13} \mathrm{Fe}_{4}$, a cubic $\beta$-phase $\mathrm{Al}(\mathrm{Fe}, \mathrm{Cu}$ ), a tetragonal $\omega$-phase $\mathrm{Al}_{7} \mathrm{Cu}_{2} \mathrm{Fe}$ ) and a recently discovered rhombohedral $R$-phase [6]. There is some evidence [10] that pentagonal and orthorhombic phases of chemical compositions close to that of the $\psi$-phase also exist at $700^{\circ} \mathrm{C}$. Optimisation of the oscillation amplitude and ball charge 
(setting 1) allowed us to repeat the results of the paper by Eckert et al [8] almost in their entirety. In addition, the detailed phase analysis (X-ray pattern fitting and comparison with the predicted spectra of model structures) allowed us to trace the path of phase evolution. We found that the following sequence of events unfolds with increasing milling time: initial mixing and interaction of powders leads to the formation of a phase having B2 structure of AlFe, i.e. superstructure of the bec structure, which had not been identified in [8] (see Fig.1). This is followed by gradual dissolution of $\mathrm{Fe}$ remainder in this phase. Presence of the other superstructure of the bcc structure, $\mathrm{AlFe}_{3}$, is also suspected.

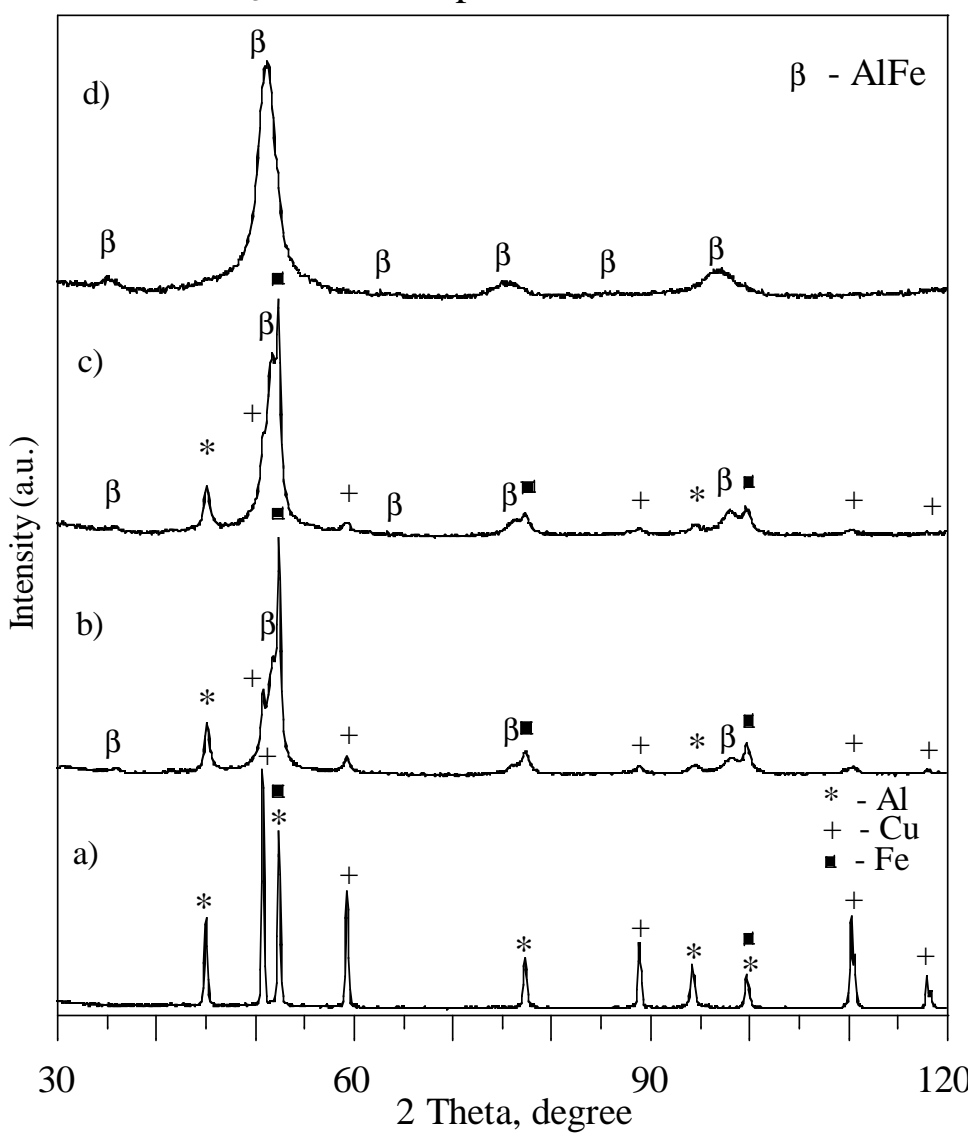

Fig.1 X-ray diffraction patterns (Co K $\alpha$ ) of mechanically alloyed $\mathrm{Al}_{65} \mathrm{Cu}_{20} \mathrm{Fe}_{15}$ powders as a function of milling time: a) initial mixture of elements; b) $8 \mathrm{~h}$; c) $16 \mathrm{~h}$; d) 32 h. $(\operatorname{Co~K\alpha })$.
In [9], the main broad peak with a double maximum and a few weaker peaks in the X-ray pattern were given as evidence of quasicrystallinity of the material milled for $15 \mathrm{~h}$. We also observed some splitting of the main broad peak after $30 \mathrm{~min}$ of milling (at higher energy level, setting 2). In our opinion, this type of X-ray patterns can not be used as a clear evidence of quasicrystallinity on its own, without being substantiated with data of either TEM or HREM investigations, since the X-ray pattern of a heavily deformed $\mathrm{Al}_{5} \mathrm{Fe}_{2}$-phase (JCPDS 29-43) can appear to be very similar.

The study of phase composition after annealing the milled powders reveals the sequence of solid-state reactions caused by heating. Table 1 presents the results of phase analysis for the samples of $\mathrm{Al}_{65} \mathrm{Cu}_{20} \mathrm{Fe}_{15}$ initial composition, which were milled for $8 \mathrm{~h}$ and then annealed for $20 \mathrm{~min}$ at different temperatures. The phases having identified structure (not chemical composition) are listed in the order of decreasing content in

Table 1. The approximate quantitative phase composition determined by fitting of experimental patterns is given for the cases when phases with unknown structures $\left(\mathrm{Al}_{5} \mathrm{Fe}_{2}\right.$ or $\left.\psi\right)$ were present in sample.

Table1. Phase composition of the mechanically alloyed powder $\mathrm{Al}_{65} \mathrm{Cu}_{20} \mathrm{Fe}_{15}$ after annealing.

\begin{tabular}{|c|c|c|}
\hline $\begin{array}{c}\text { Temperature of } \\
\text { annealing, }{ }^{\circ} \mathrm{C}(\mathrm{K})\end{array}$ & $\begin{array}{c}\text { Qualitative phase } \\
\text { composition }\end{array}$ & $\begin{array}{c}\text { Approximate quantitative phase } \\
\text { composition (volume fraction, \%) }\end{array}$ \\
\hline As-milled & $\mathrm{AlFe},\left(\mathrm{AlFe}{ }_{3}\right), \mathrm{Al}, \mathrm{Fe}, \mathrm{Cu}$ & $54.6,30.9,10.7,3.8$ \\
\hline $250(523)$ & $\mathrm{Al}_{2} \mathrm{Cu}, \mathrm{Fe}_{3} \mathrm{Al}, \mathrm{Fe}, \mathrm{Al}$ & $42.4,32.6,16.6,8.4$ \\
\hline $400(673)$ & $\mathrm{Al}_{4} \mathrm{Cu}_{9}, \mathrm{Al}_{5} \mathrm{Fe}_{2}, \mathrm{Al}_{7} \mathrm{Cu}{ }_{2} \mathrm{Fe}, \mathrm{Fe}$ & $\sim 50, \sim 25, \sim 20, \sim 5$ \\
\hline $525(798)$ & $\mathrm{AlFe}, \mathrm{Al}_{5} \mathrm{Fe}_{2}, \mathrm{Al}_{4} \mathrm{Cu}_{9}, \mathrm{Fe}$ & $\sim 35, \sim 35, \sim 25, \sim 5$ \\
\hline $600(873)$ & $\mathrm{AlFe} \psi, \mathrm{Fe}$ & $\sim 50, \sim 45, \sim 5$ \\
\hline $800(1073)$ & $\mathrm{AlFe}, \Psi$ & $\sim 70, \sim 30$ \\
\hline
\end{tabular}


A phase with the AlFe-structure obtained as the result of milling happens to be metastable, since this phase decomposes at $200{ }^{\circ} \mathrm{C}$, while the stable AlFe ( $\beta$-phase) forms only after the annealing at $525{ }^{\circ} \mathrm{C}$. It is also clear that the final phase composition differs from the one expected: the

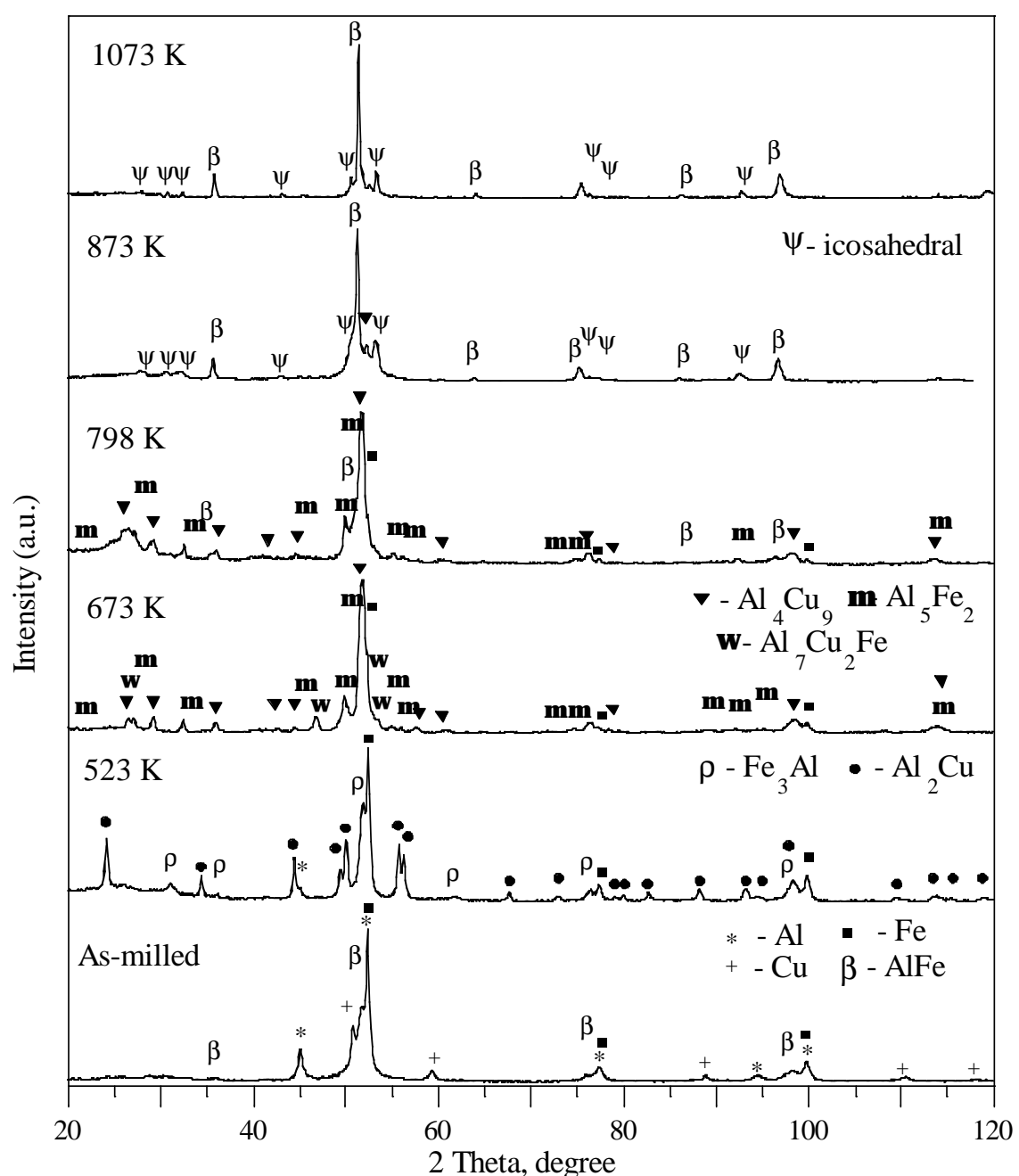

Fig.2 Variation of the X-ray patterns of mechanically alloyed $\mathrm{Al}{ }_{65} \mathrm{Cu}_{20} \mathrm{Fe}_{15}(8 \mathrm{~h})$ with annealing temperature $(\mathrm{Co} \mathrm{K} \quad \alpha)$. presence of the AlFe $(\beta$ phase) intermetallic compound signifies that the starting chemical composition of the mixture $\left(\mathrm{Al}_{65} \mathrm{Cu}_{20} \mathrm{Fe}_{15}\right)$ is not suitable for obtaining single phase quasicrystalline material by the combination of mechanical alloying and annealing.

Further analysis of diffraction data, additional milling experiments, and SEM investigations allowed us to identify three factors which have significant influence on the phase composition of mechanically alloyed Al$\mathrm{Cu}-\mathrm{Fe}$ powders:

1. We believe that inhomogeneity in the asmilled powders leads to the complex consequence of solid-state transformations during heating, when new phases form as result of levelling of chemical composition. SEM investigation of the asmilled (setting 1, 8h)

powders of $\mathrm{Al}_{65} \mathrm{Cu}_{20} \mathrm{Fe}_{15}$ initial composition confirmed their inhomogeneity. Large particles of the as-milled material obtained during cleaning of the vial from the thick adherent layer forming were dramatically enriched in $\mathrm{Al}$. There is also clear inhomogeneity in the distribution of $\mathrm{Cu}$ and $\mathrm{Fe}$ in the as-milled powder. Some inhomogeneity remains even in the powder annealed at $600^{\circ}$ $\mathrm{C}$, which is most obvious for $\mathrm{Fe}$ (see Table 1). One can conclude, therefore that, since longer milling times tend to produce more homogeneous distributions of the elements, this may promote the formation of quasicrystals after annealing.

However, the data presented in [8] and [9], as well as our results, show that longer milling leads to decreasing of the $\psi$-phase content in the powder after annealing. In our opinion, the sticking effect of the more ductile $\mathrm{Al}$ powder, and possible contamination of the mixture by $\mathrm{Fe}$ due to wear of vial walls and bearing balls, shift the chemical composition towards the Fe end of the phase diagram.

Mechanical alloying/milling, besides, is well known to promote disordering in intermetallics [11]. Moreover, it has been found [12] that milling of the stable quasicrystalline phase in $\mathrm{Al}-\mathrm{Cu}-\mathrm{Fe}$ system results in the formation of the amorphous phase. It is hence our opinion that extended milling is unlikely assist to the formation of quasicrystalline phases.

2. Since Fe particles persist even after annealing at $600^{\circ} \mathrm{C}$, we believe that the variety of intermetallic phases appearing as a result of heating reflects the gradual dissolution of $\mathrm{Fe}$ particles. This leads to the formation of intermetallic compounds having chemical composition 
different from $\mathrm{Al}_{65} \mathrm{Cu}_{20} \mathrm{Fe}_{15}$. The dissolution of $\mathrm{Fe}$ particles and homogenisation by diffusion seem to be the controlling factors in the formation of quasicrystals. High temperature annealing may be sufficient for obtaining quasicrystals, especially after short milling times.

3. Unfortunately, no information about the choice or effect of the annealing atmosphere is given in [8,9]. However, according to [2], oxidation of $\mathrm{Al}$ in the quasicrystalline $\psi$-phase results in the appearance of the AlFe-phase. In our DTA experiments, heating the as-milled powder and maintaining it at $800^{\circ} \mathrm{C}$ in nitrogen revealed a strong exothermic peak, which disappeared if annealing was performed under purified argon atmosphere. We found that the annealing atmosphere significantly influences the phase composition of the processed powder, with the volume fraction of the quasicrystalline $\psi$-phase being significantly higher after annealing in argon, although in both cases the final powders contained some AlFe crystalline intermetallic phases alongside the quasicrystalline $\psi$-phase.

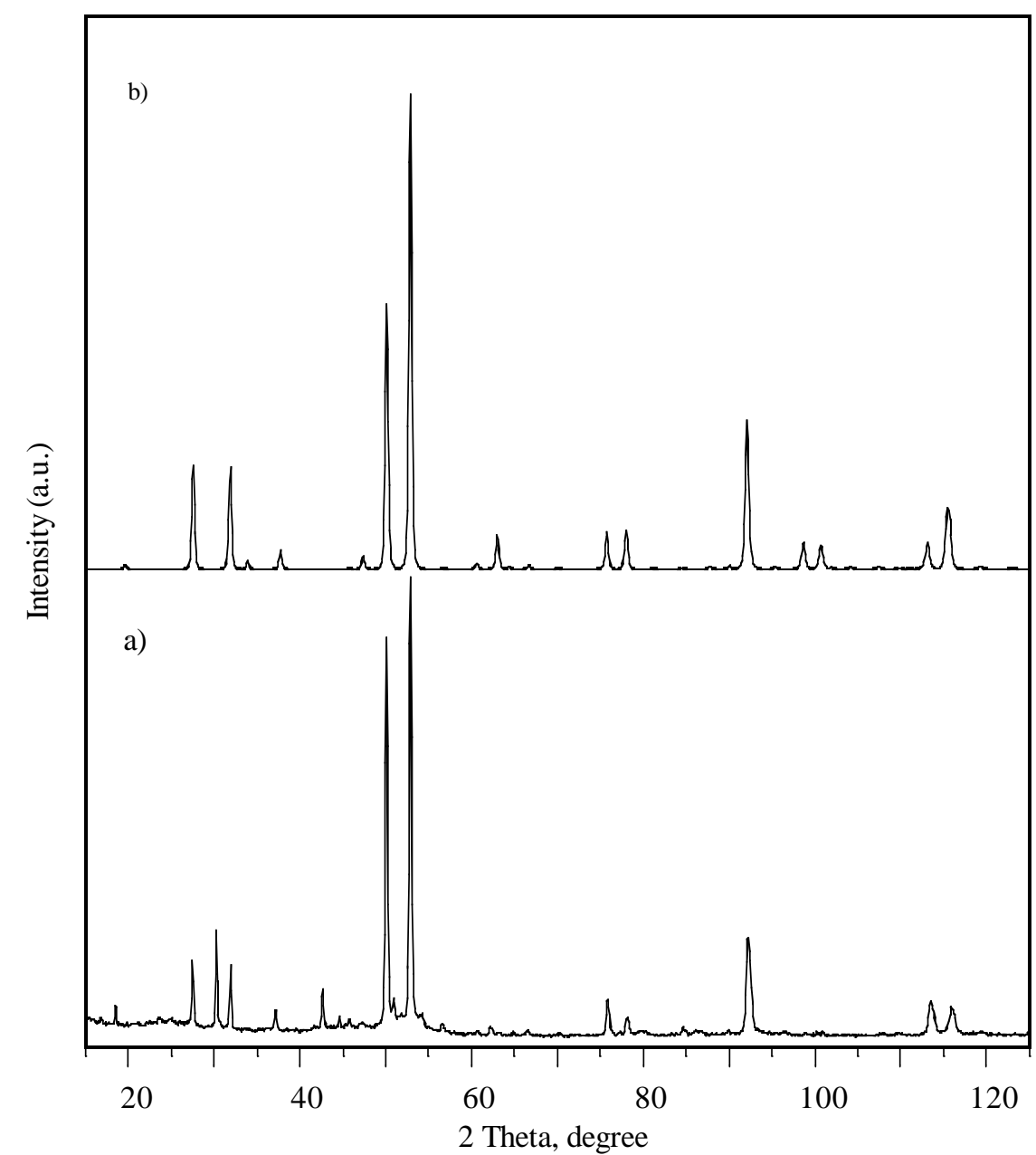

Fig.3 X-ray diffraction patterns: a) experimental from annealed at $1073 \mathrm{~K}$ for 30 min mechanically alloyed powder $\mathrm{Al}{ }_{70} \mathrm{Cu}_{20.3} \mathrm{Fe}_{9.7}$;

b) modelled spectrum of primitive quasicrystalline structure for chemical composition $\mathrm{Al}_{63.5} \mathrm{Cu}_{24.5} \mathrm{Fe}_{12}$. (Co K $\left.\alpha\right)$.
We conclude that in order to obtain single-phase

quasicrystalline material by mechanical alloying in combination with subsequent heat treatment, certain modifications to the preparation procedure must be introduced. These are:

1. The initial mixture of elements must contain an increased amount of $\mathrm{Al}$ and less $\mathrm{Fe}$, compared to the $\mathrm{QC}$ composition.

2. More energy-intensive milling conditions are preferred, in order to increase the milling temperature and provide more intimate mixing.

3. Purified noble gas atmosphere is preferred during annealing.

These recommendations were applied in search for the best formulation for the initial mixture of

elemental powders [13]. After testing multiple compositions, single phase quasicrystalline material was successfully obtained after mechanical alloying of the mixture $\mathrm{Al}_{70} \mathrm{Cu}_{20.3} \mathrm{Fe}_{9.7}$. Milling times in the range $0.25-1 \mathrm{~h}$ at setting 2, and annealing for $10-20$ min under argon at $800^{\circ} \mathrm{C}$, followed by furnace cooling, resulted in obtaining single-phase F-type quasicrystalline material. Experimental X-ray pattern shown in Fig. 3 is in perfect agreement with the one presented in [14] for the stable quasicrystalline alloy $\mathrm{Al}_{63.5} \mathrm{Cu}_{24.5} \mathrm{Fe}_{12}$ obtained by melting of pure elements and 
annealed at $730{ }^{\circ} \mathrm{C}$ for 24 hours. The modelling of X-ray patterns for the quasicrystalline phase having composition $\mathrm{Al}_{63.5} \mathrm{Cu}_{24.5} \mathrm{Fe}_{12}$ with the primitive structure was performed using a specially written computer program ICOS2 [15], and revealed significant differences between the spectra of the primitive and face-centred quasicrystalline structures. ICOS2 generates tiling of the decorated Ammann rhombohedra and evaluates the structural amplitude for the "unit cell" differing from its crystal counterpart by the presence of extra zonohedra-related form factors. The decoration of the Ammann rhombohedra by atomic spices was carried out using the available information about the atomic structure of the $\mathrm{Al}-\mathrm{Cu}-\mathrm{Li}$ quasicrystals [16]. Noticeable differences between the patterns for the primitive and face-centred quasicrystalline structures can be attributed to the higher symmetry of the 6-dimensional lattice.

Modelling of the X-ray patterns for the F-type quasicrystalline structure is in progress.

\section{CONCLUSIONS}

Advanced X-ray diffraction pattern interpretation techniques were applied to gain better understanding of solid-state reactions in mechanically alloyed $\mathrm{Al}-\mathrm{Cu}-\mathrm{Fe}$ powders. These techniques allowed the identification of the set of intermetallic phases forming during transformations taking place under mechanical alloying and subsequent annealing.

Some factors influencing the formation of the quasicrystalline icosahedral phase were identified. Favourable conditions promoting the formation of single phase QC material were formulated and successfully applied. The approach provides a simple and powerful technique for producing large amounts of quasicrystalline powder for further applications.

\section{ACKNOWLEDGEMENTS}

This work was supported by NATO/Royal Society fellowship program under Grant No 97A/NATO and Russian Foundation for Basic Research under Grant No 97-02-17915, which are gratefully acknowledged.

\section{REFERENCES}

[1] J.M Sordelet, J.M. Dubois, MRS Bulletin 22, 34 (1997).

[2] M.F. Besser, T. Eisenhammer, MRS Bulletin 22, 59 (1997).

[3] S.S. Kang, J.M. Dubois, J.von Stebut, J.Mater.Res. 8, 2471 (1993).

[4] A.M. Viano, E.H. Majzoub, R.M. Straud, M.J. Kramer, S.T. Misture, P.C. Gibbons, K.F. Kelton, Phil. Magazine A 78, 131 (1998).

[5] F.W. Gayle, A.J. Shapiro, F.S. Biancaniello, W.J. Boettinger, Metall. Trans. A 23A, 2409 (1992).

[6] D. Gratias, Y. Calvayrac, J. Devaud-Rzepski, F. Faudot, M. Harmelin, A. Quivy, P.A. Bancel, J. Non-Crystall. Solids 153-154, 482 (1993).

[7] E.V. Shelekhov, Proc. of Russian National conference on the Application of X-ray and Synchrotron Radiation, Neutrons and Electrons, 25-29 May 1997, Dubna, Russia. 3, 316 (1998).

[8] J. Eckert, L. Schultz, K. Urban, Acta Metall. Mater. 39, 1497 (1991).

[9] N.Asahi, T.Maki, Sh. Matsumoto, T. Sawai, Mat. Sci. Eng. A 181-182, 841 (1994).

[10] C. Janot, Quasicrystals: A Primer. Clarendon Press. Oxford. 1994.

[11] C.C. Koch, Mater. Sci. Forum 88-90, 243 (1992).

[12] S. Nasu, M. Miglerini, K.N. Ishihara, P.H. Shigu, Journal of the Physical Society of Japan 61, 3766 (1992).

[13] A.I. Salimon, A.M. Korsunsky, E.V. Shelekhov, T.A. Sviridova, to be published.

[14] C. Janot, M. Audier, M. de Boissieu, J.M. Dubois, Europhys. Lett. 14, 355 (1991).

[15] E.V. Shelekhov, Yu.A. Skakov, Mater. Sci. Eng. A. 134, 908 (1991).

[16] Y. Shen, S.J. Poon, W. Dmowski, T. Egami, G.J. Shifled, Phys. Rev. Lett. 58, 247 (1987). 